\title{
Over 35 years, integrated pest management has reduced pest risks and pesticide use
}

\author{
by Peter B. Goodell, Frank G. Zalom, Joyce F. Strand, Cheryl A. Wilen and Karey Windbiel-Rojas
}

Pests and their interactions with crops, ecological landscapes and animals are in continuous flux - they are never static. Pest severity increases or decreases depending on environmental conditions and changes in production or pest control practices. Pest management is made even more challenging by exotic and newly invasive pests. Over its 35-year history, the UC Agriculture and Natural Resources Statewide IPM Program has supported research and extension that has decreased risks of crop losses, improved treatment programs for invasive and endemic pests, and reduced the use of pesticides and their impact on the environment and human health. Its publications are widely used among growers, pest control advisers, research institutions, state agencies, agricultural organizations and gardeners; and integrated pest management has been adopted statewide in agriculture, as well as in managed landscapes and urban areas.

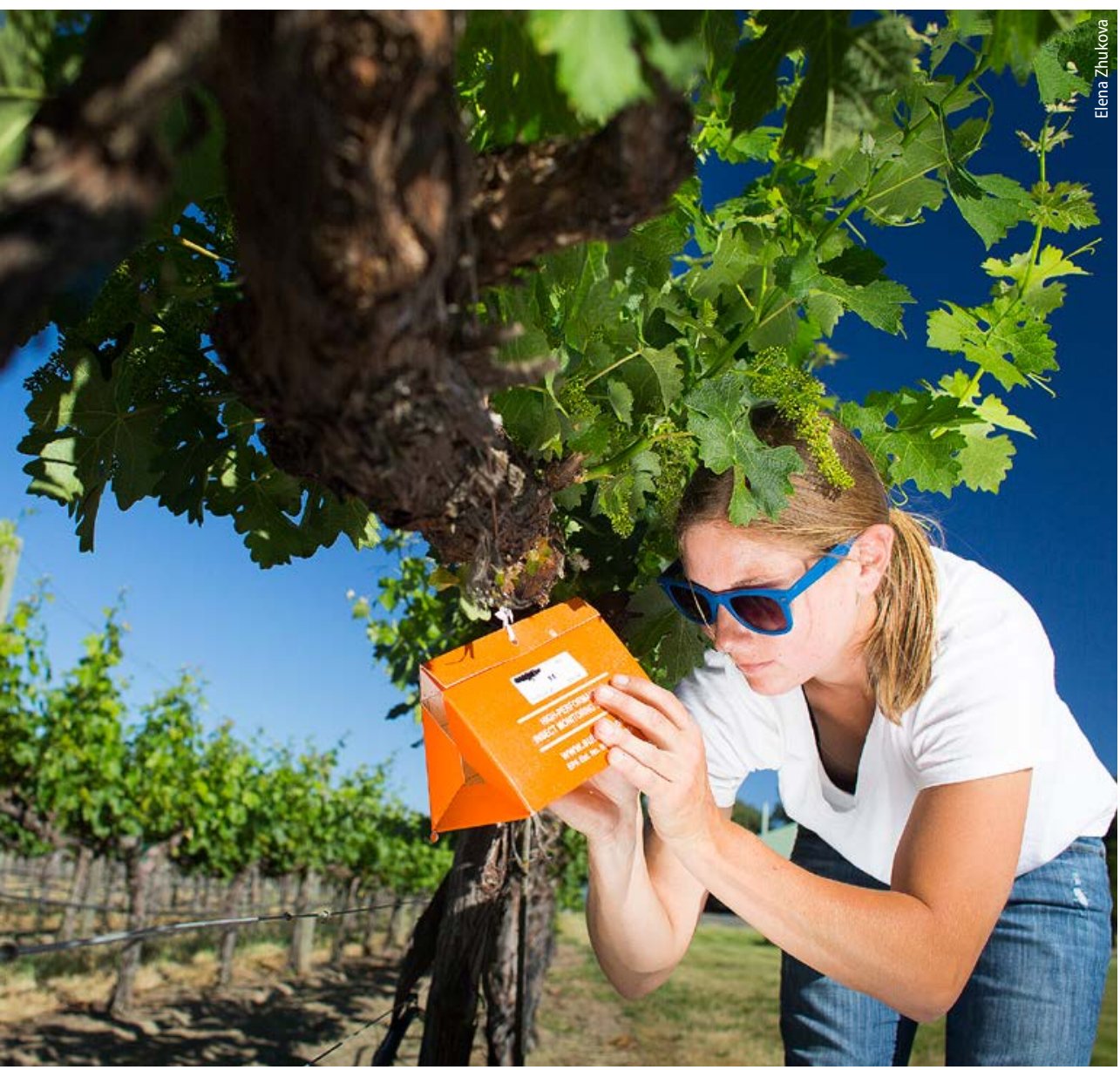

In 2001, UC IPM and the Center for Invasive Species Research established a grant program to support research of exotic and invasive pests and diseases such as European grapevine moth, glassy-winged sharpshooter and Pierce's disease. Lab assistant Emily Kuhn checks a pheromone trap for European grapevine moth in a vineyard at UC Davis Oakville Research Station, Napa County. The moth, which is endemic to Mediterranean Europe, was first discovered in California in 2009.
Thtegrated pest management (IPM) is a systems approach to pest management. Because of the diverse situations in which pests occur, what constitutes IPM best practices may vary with time, location and other circumstances. IPM considers each available control tactic for example, cultural, biological, chemical - and often applies a combination of tactics to enhance overall effectiveness and reduce reliance on any single tactical approach. It relies on extensive knowledge of the pest, the crop and the environment in which it exists. Regularly and frequently monitoring the status of a pest, its natural enemies and the site is fundamental to IPM decision making.

In 1979, the California legislature provided funding to the UC Division of Agricultural Sciences (now Agriculture and Natural Resources, ANR) to establish the UC Statewide Integrated Pest Management Program (UC IPM). The broad goals of the original program have remained consistent:

- Increase use of ecologically based integrated pest management programs.

- Provide leadership in IPM, including building coalitions and partnerships that link with communities and public agencies.

- Increase the predictability and effectiveness of pest management techniques.

- Develop science-based pest management programs that are economically and environmentally sustainable and socially appropriate.

- Protect human health and the environment by reducing risks caused by pests and pest management practices.

Since 1980, UC IPM scientists have worked with other ANR scientists to

Online: http://californiaagriculture.ucanr.edu/ landingpage.cfm?article=ca.v068n04p153\&fulltext=yes doi: 10.3733/ca.v068n04p153 
conduct research on specific pests and pest systems and develop economically feasible and environmentally sound IPM programs. These programs have been extended to California growers by IPM advisors and other UC Cooperative Extension (UCCE) advisors.

Experience has shown that developing and implementing an IPM program is only the first challenge. Maintaining an IPM program in which the pest and its damage are managed economically and with minimum risk to the environment and human health is often not easily achieved. One goal of a mature IPM system is to establish equilibrium within the ecosystem, such that frequent chemical intervention is not required. This goal is rarely achieved, however, due to the dynamic nature of pests, horticultural practices, crop values, new pest control technologies, new regulations and the range of possible ecological landscape interactions.
A stable IPM system can also be upset by the introduction of an exotic pest. Opportunities for UC scientists to conduct research on the management of exotic pests in California are extremely limited due to regulated early response programs by federal and state agencies. However, once these invaders become established, they can be studied as part of the ecosystems they have invaded, and managed in an IPM systems framework. While virtually all of the pests for which UC IPM has guidelines are established in California, a significant number of them, $40 \%$ or more, are not endemic but were invaders that accompanied the movement of people, food or plant material into the state. Some of these pests, including sudden oak death, thousand cankers disease, giant reed, Sahara mustard, ash whitefly, sweetpotato whitefly biotype B, glassy-winged sharpshooter, olive fruit fly and spotted wing drosophila, were first detected and became problematic after 1980, within the timeframe of UC IPM. Most of the invaders, however, have been established for a half century or more.

Development of IPM programs for key pests, whether endemic, invasive but long established, or more recently introduced, shares many commonalities. It requires an understanding of the pest's biology and interactions with the crop to develop an integrated approach that favors the crop over the pest. To be effective, program development must include the skills and knowledge of other UC researchers and the results must be distributed widely. This challenge is largely met through competitive grant funds, production of educational materials and demonstration of new practices in local fields and orchards.

\section{UC IPM overview}

UC IPM was built upon the successful land-grant university research and extension model. Beginning in 1979, UCCE

\section{Publications provide a foundation of IPM practices}

$\mathrm{UC}$ IPM's publications and website (ipm.ucdavis.edu) have greatly contributed to the statewide adoption of IPM practices by growers, landscape professionals and gardeners. To date, there are 19 books in print, and the website has multiple layers of information, including pest management guidelines for 65 crops. Together, the materials present a foundation of IPM practices for California crops and urban settings. They are broadly cited in technical
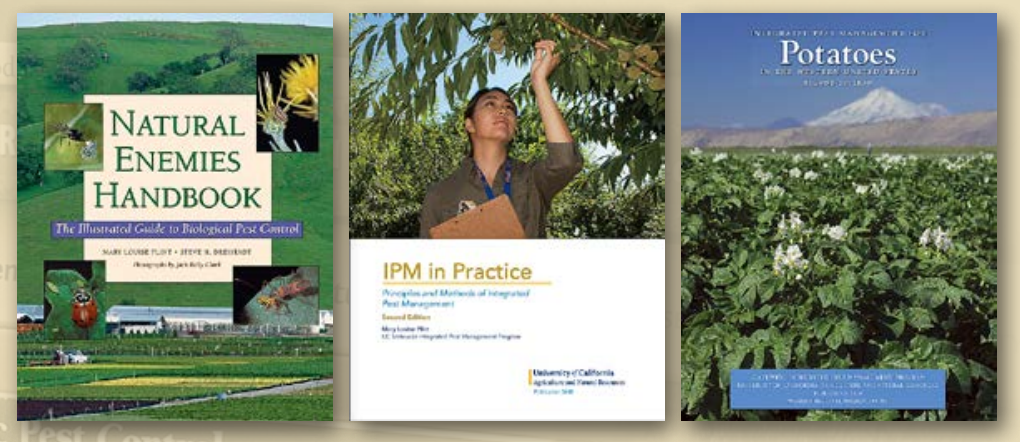

journals, agency reports and nontechnical articles, and the practices they detail have also been adopted by agricultural organizations and used in many self-assessment and certification programs (e.g., Lodi-Woodbridge Wine Grape Commission, San Joaquin Sustainable Farming Project). To see the full range of UC IPM products, visit ipm. ucdavis.edu/IPMPROJECT/pubs.html.

Manuals and books. IPM manuals have been developed and updated for 17 crops, providing information on pest biology and nonchemical management of important pests, as well as other management tactics. Other reference books include IPM in Practice and Handbook of Natural Enemies.

\section{Pest Management Guidelines (PMGs), Pest Notes, Quick Tips and} Pest Alerts. There are 47 PMGs representing 65 crops and crop groups available on the UC IPM website. The guidelines provide brief descriptions of a pest's biology; damage symptoms; and monitoring support; plus biological, cultural and chemical control practices; options for organic production; and illustrations for diagnostic purposes.

Since 2000, the Pest Notes have addressed pests in urban and landscape settings, with 166 Notes currently available. Pest Alerts are brief overviews that highlight new pests invading California. Quick Tips are based on Pest Note subjects but provide summaries for easy reference.

The PMGs and Pest Notes also contain information on pests of quarantine concern for exports, such as the oriental fruit moth for stone fruit exports to Mexico, and the Fuller rose beetle for citrus exports to Japan; IPM management options are in-

cluded for these insects.

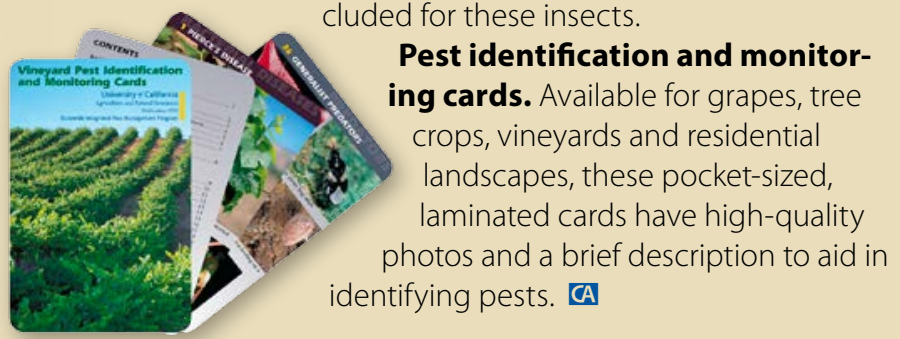


professionals were hired to consolidate, test and deliver applied research findings on pest management to end-users. The program included a computer network to process and disseminate data and information required for effective IPM programs, and a designated writing staff to produce IPM manuals and other documents that contained practical information for growers and other pest management decision makers.

Until 2009, UC IPM sponsored a competitive research grants program, which generated new IPM knowledge and practices to address gaps in pest management systems and improve upon existing practices; it supported more than 450 IPM-related projects. By 1990, at the conclusion of UC IPM's first decade, 578 publications had been produced based on project-funded research. A 1989 survey indicated that $36 \%$ of the principal investigators found evidence of a reduction in pesticides as a result of UC IPM-funded research (Grieshop and Pence 1990).

Some of the notable successes from UC IPM-sponsored research involved then-recent invaders, for example, the ash whitefly. A pest of ornamental trees first detected in California in 1988, the ash whitefly became a considerable nuisance for homeowners and businesses because of the sticky film that covered everything underneath an infested tree. A competitive grant was provided to researchers

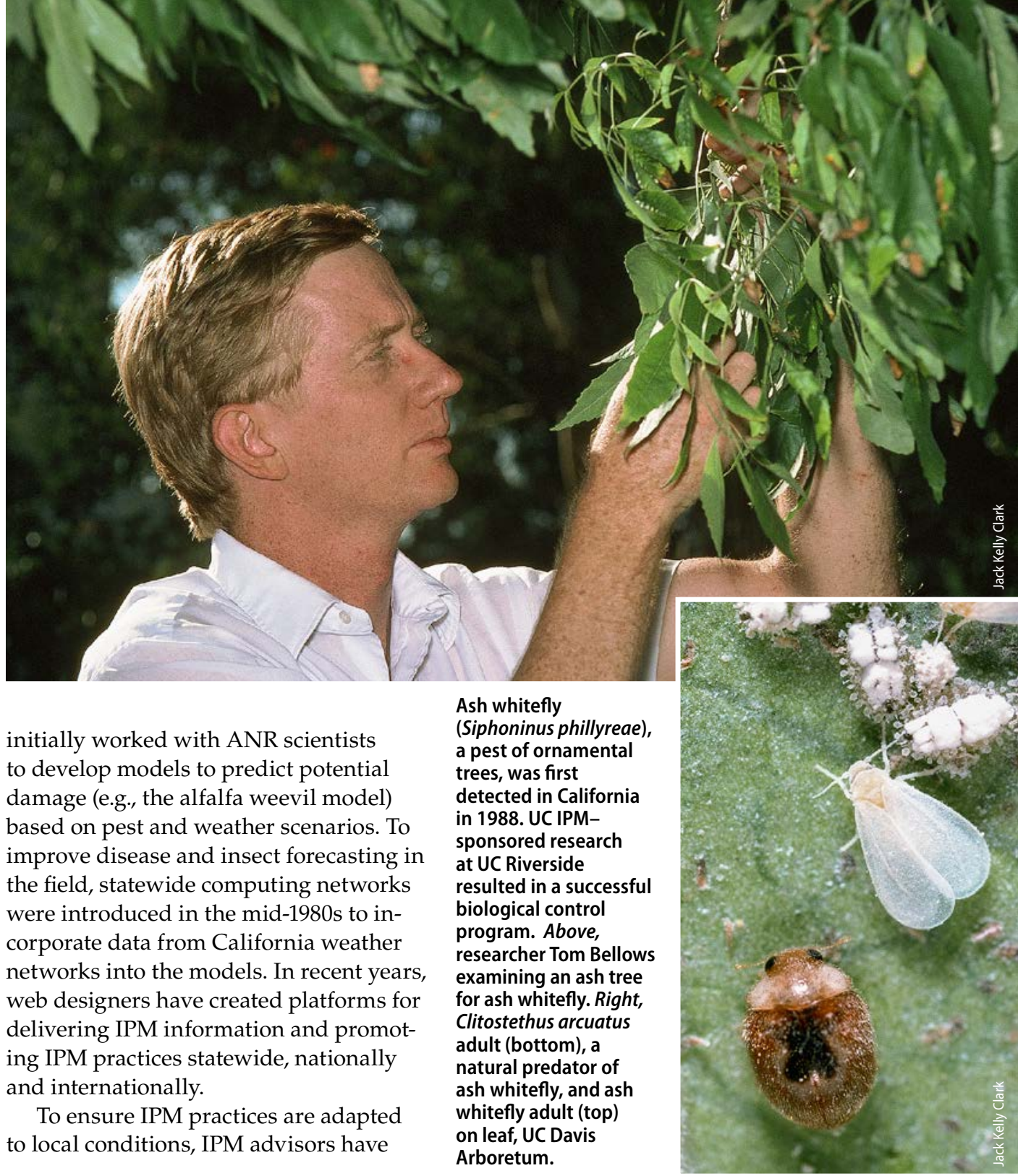

\section{In recent years, web designers have created platforms for delivering IPM information and promoting IPM practices statewide, nationally and internationally.}

at UC Riverside to study its biology and support foreign exploration for biological control agents. The research resulted in a permanent and successful management program utilizing biological control as its primary management approach.

In the early 1980s, technical writers and editors developed comprehensive IPM manuals for 15 crops and created pragmatic and easily updatable guidelines for managing pests of specific crops. Other innovative publications followed, including additional books, Pest Notes, and pest identification and monitoring cards (see sidebar, page 154).

Computing and network technology have been critical to UC IPM's information delivery. Computer programmers been distributed throughout the state to implement IPM through field research and extension. One of their key roles is to support local production farm advisors in integrating the latest pest management practices into local cropping systems. Equally important, IPM advisors communicate locally identified pest management needs to campus-based researchers.

\section{Foundation of UC IPM, 1980 to 1986}

During the formative years of UC IPM, nine major crops were highlighted for IPM research and extension: alfalfa, almond, cereals, citrus, cotton, grapes, rice, tomatoes and walnuts. The selection of these crops was largely based on their value, acreage and pesticide use. Research and extension projects were developed by cross-disciplinary teams of key scientists from all three UC campuses with colleges of agriculture (Davis, Berkeley and Riverside) and UCCE academics from critical counties in which the crops were produced. Each team focused their research efforts on the biology of the pests and natural enemies in the cropping system and the crop plant's development to better understand the relationship among those three key elements of pest population growth. Key research topics included improved decision making, better timing of pesticide intervention, increased understanding of crop and pest interactions, and alternative pest control approaches.

Crop modeling was emphasized to increase knowledge of environmental influences on pest and crop dynamics. A crop model is a mathematical simulation of the growth and development of a plant 
UC IPM increases its urban and community IPM footprint

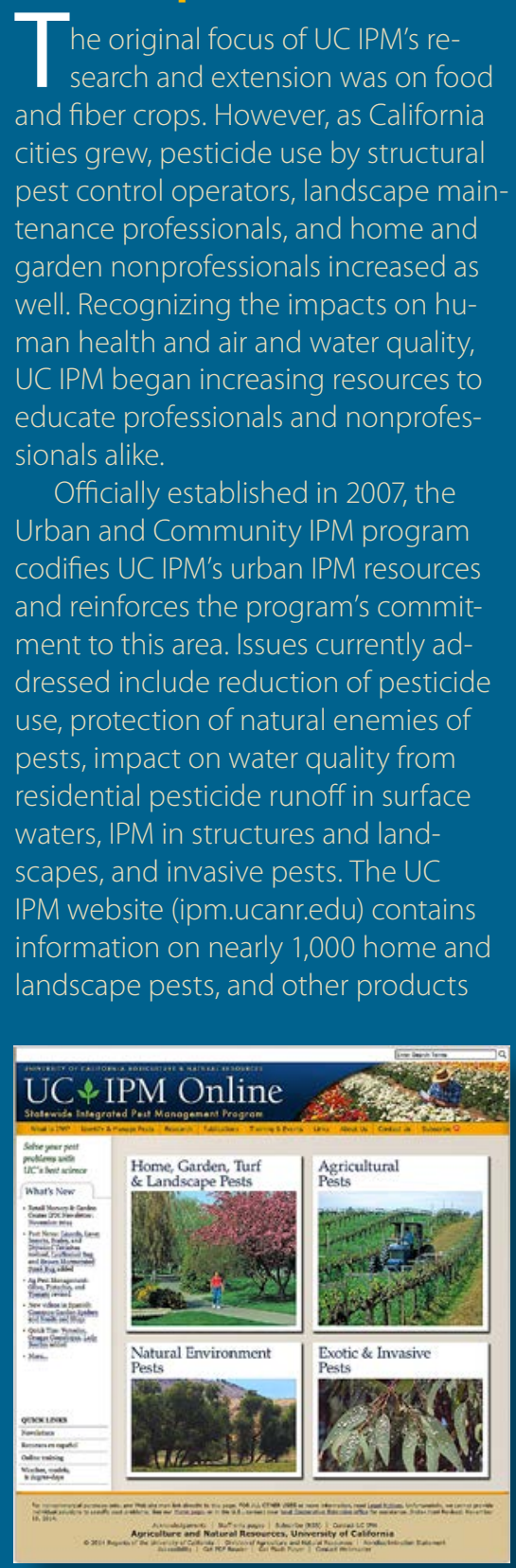

developed for urban audiences include videos and training materials for UC Master Gardeners, schools and retail nursery staff. To keep audiences current on IPM news, articles and updates are frequently posted on the Pests in the Urban Landscape blog (ucanr.edu/ blogs/UCIPMurbanpests/index.cfm) and in newsletters for retail nursery and garden center staff, landscapers and structural pest management professionals. CA

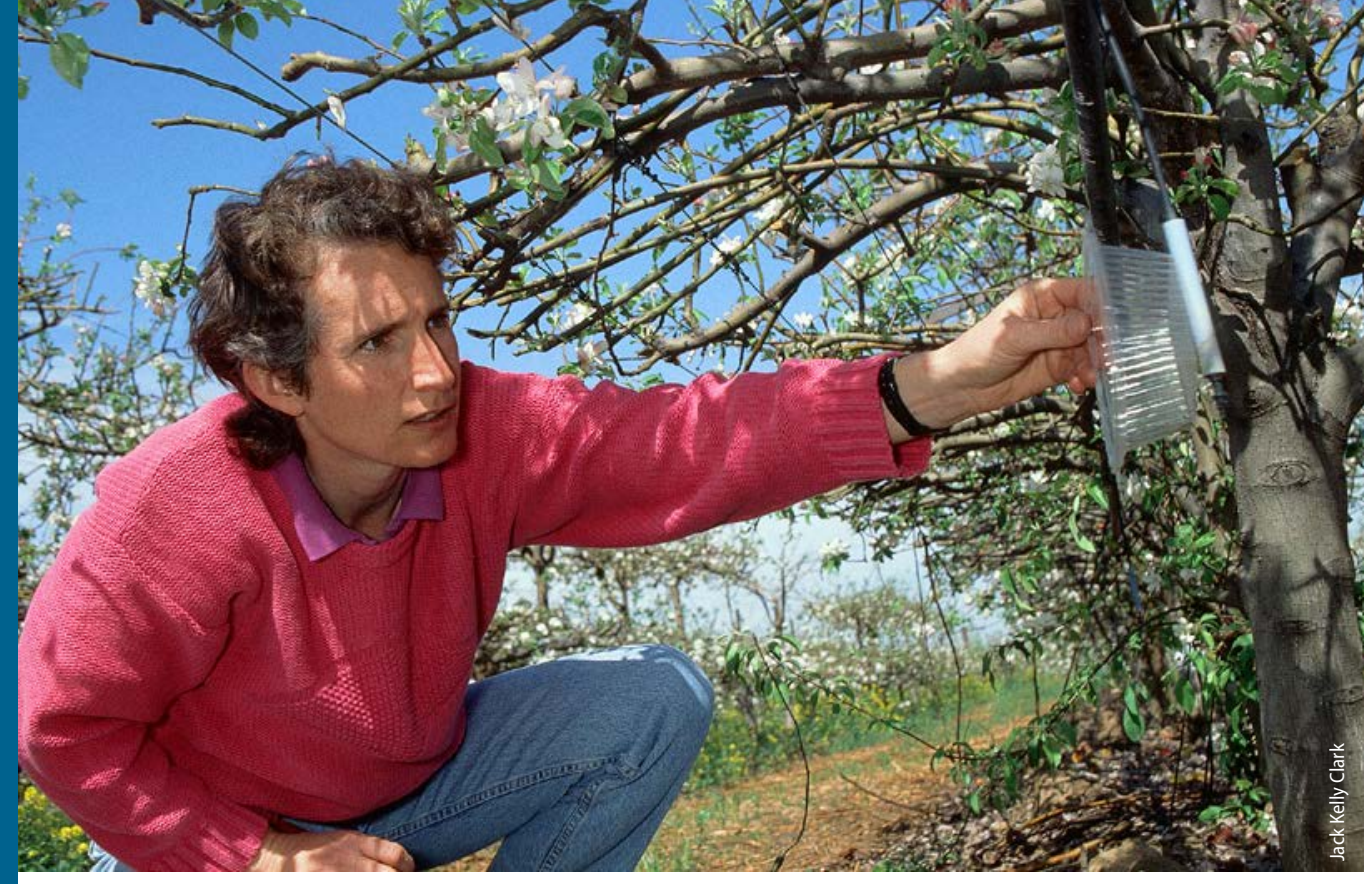

A survey of IPM research grant awardees found that $38 \%$ of projects conducted between 1989 and 1999 focused on biological control. Farm Advisor Janet Caprile reaches into trellised apples to release Aphidoletes predatory midge for control of rosy apple aphid in Contra Costa County.

(alfalfa, cotton, grape) that allows for stress caused by the environment and pests to be incorporated. Such models greatly aid the understanding of croppest interactions by predicting the impact pests can have on yield.

Sampling methodology was refined to be reliable, accurate and easy to use, including binomial sampling for spider mites in cotton and almonds and for caterpillar pests in tomato. The 1989 survey conducted by Grieshop and Pence revealed that $43 \%$ of growers and $43 \%$ of pest control advisers (PCAs) were using publications and information developed by UC IPM-sponsored programs. A complete listing of research and extension projects supported can be found in Pence (1990).

\section{New focus, new pests, 1986 to 2000}

In 1986, UC IPM convened a meeting of stakeholders and UC IPM staff to review the program's research and extension focus. Stakeholders consisted of PCAs, growers, UC campus faculty from Berkeley, Davis and Riverside, and public agencies such as California Department of Pesticide Regulation and California Department of Food and Agriculture. In order to address pest issues in a wider set of crops, UC IPM's direction was changed from crop-based projects to practice-based projects. This change expanded the opportunity for studying pests and diseases on many more crops, and in noncrop sites, such as public spaces, natural areas and animal agriculture. During this period, a wide variety of projects were funded on topics including improving pest monitoring and treatment decision support, increasing the understanding of relationships between pests, crops and natural enemies (applied field ecology) and improving the use of nonchemical management approaches such as biological control, cultural control and biorationale use of biotic agents or chemicals.

A survey of IPM research grant awardees by Klonsky and Shouse (2000) reported almost three-quarters of the projects between 1989 and 1999 were directed toward reducing pesticide use and two-thirds of the projects were undertaken to improve the efficacy of pest control. Reflecting changes in the regulatory climate toward pesticides during the 1990 s, $38 \%$ of the projects focused on biological control and use of indigenous natural enemies and 13\% investigated microbial and botanical pesticides. Overall, $30 \%$ of the projects produced entirely nonchemical pest control procedures.

It was during this period that UC IPM began to address, through its competitive grants program and with local collaborations with PCAs and growers, the management of new pests that were affecting existing IPM programs. For example, the appearance of sweetpotato whitefly biotype B, a genetic variant of Bemisia tabaci, in the early 1990s, created a crisis for the production of cotton and other crops, such as melons, in the 
Imperial Valley and the southern San Joaquin Valley. The existing management program was insufficient to prevent late-season outbreaks of the new biotype that resulted in unacceptable cotton lint covered in sticky honeydew. Research by scientists from UC Davis, UC Riverside and UCCE, partially funded by UC IPM, and extension of new management tactics coordinated by IPM advisors ultimately resulted in the whitefly's successful management. Other newly discovered invaders targeted by UC IPM funding included blue gum psyllid, Russian wheat aphid and giant whitefly on urban plants.

\section{Changing regulations, more new pests, 2000 to 2012}

In 2001, UC IPM expanded its role in addressing exotic and invasive pests by collaborating with the Center for Invasive Species Research at UC Riverside through its UC Exotic/Invasive Pests and Diseases Research Program to establish a competitive grant program funded through the predecessor of USDA's National Institute for Food and Agriculture. From 2001 to 2009, 102 projects were supported that addressed specific exotic and invasive pests and diseases, including European grapevine moth, glassy-winged sharpshooter and Pierce's disease (see pages 125-141). Since the emergence of a new pest may result in pesticide applications that are detrimental to an established IPM system, the funded projects studied the effects of those applications, with results often leading to useful revisions of the UC IPM guidelines. Information on exotic and invasive pests, including management guidelines, is now disseminated in all UC IPM materials and at ipm.ucdavis.edu/ EXOTIC/index.html.

Concern about the impact of pesticides on humans and the environment intensified during the 1990s. For example, legislation such as the Food Quality Protection Act of 1996 resulted in increasingly stringent enforcement of environmental regulations. UC IPM worked closely with growers and regulatory agencies to identify and implement appropriate management strategies to decrease risks posed from pesticide use. Of particular note was the reduction of the use of organophosphate insecticides as dormant sprays in orchards during sensitive periods of rainfall and fog to protect surface water quality, air quality and wildlife, including raptors. Since IPM is only one component necessary for environmental research on pesticide mitigations, a diverse group of scientific expertise needed to be assembled. UC IPM provided leadership in coordinating projects to identify and extend mitigation practices and alternatives to the high-risk organophosphate insecticides. The use of these insecticides subsequently declined dramatically across California orchard crops as growers turned to winter orchard floor management, reduced-risk insecticides and alternative treatment timings.

Publication of the Natural Resources Defense Council white paper "More IPM Please" (Hamerschlag 2007) focused public attention on the role of IPM in the conservation of natural resources. In response to the white paper, UC IPM began working closely with USDA Natural Resources and Conservation Service (NRCS) to develop an IPM training program for NRCS staff. The training emphasized IPM practices that mitigate the impacts of pest management activities on soil, water, air, plants and animals. This partnership with NRCS in California provided an opportunity to increase IPM adoption by linking activities to NRCS-recognized practices for cost sharing (Brewer and Goodell 2012). For example, as part of NRCS whole farm resource planning, the inclusion of an IPM plan was encouraged to identify potential mitigation activities related to pest management.
Now in its fourth decade, UC IPM continues to collaborate successfully with UC campuses, UC Cooperative Extension, commodity organizations and governmental agencies. It provides a platform for the organization, coordination and leadership needed for addressing pests and pest-related issues that threaten California crops, rangeland, public spaces and residential landscapes. $C A$

\footnotetext{
P.B. Goodell is UC Cooperative Extension (UCCE) Advisor, IPM, Kearney Agricultural Research and Extension Center; F.G. Zalom is Professor, UCCE Specialist and Entomologist, Agricultural Experiment Station, UC Davis, J.F. Strand is IPM Coordinator Emeritus; C.A. Wilen is Area IPM Advisor, San Diego County; and K. Windbiel-Rojas is Associate Director for Urban \& Community IPM and Area IPM Advisor.
}

\section{References}

Brewer MJ, Goodell PB. 2012. Approaches and Incentives to Implement Integrated Pest Management which Addresses Regional and Environmental Issues. Ann Rev Entomol 57:41-59.

Grieshop JI, Pence RA. 1990. Research results: Statewide IPM's first 10 years. Calif Agr 44(5):24-6.

Hamerschlag K. 2007. More Integrated Pest Management Please: How USDA Could Deliver Greater Environmental Benefits from Farm Bill Conservation Programs. Natural Resources Defense Council Issue Paper, Feb 2007. 23 p. www.nrdc.org/health/pesticides/ipm/contents.asp.

Klonsky K, Shouse B. 2000. IPM research profiled: 10 year trends. Calif Agr 54(6):20-1.

Pence B. 1990. Bibliography of Research, 1980-1990. Publication 10. University of California Statewide

Integrated Pest Management Project. 57 p.
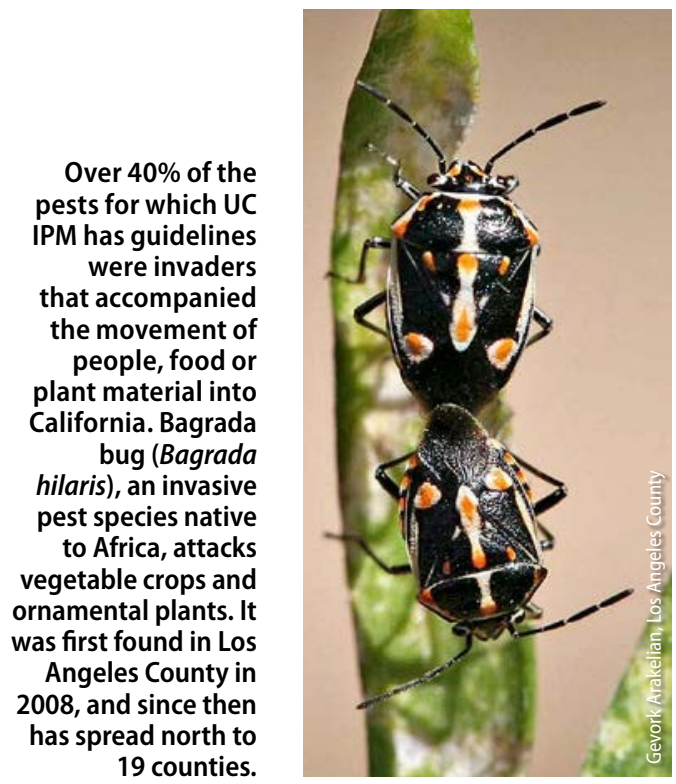

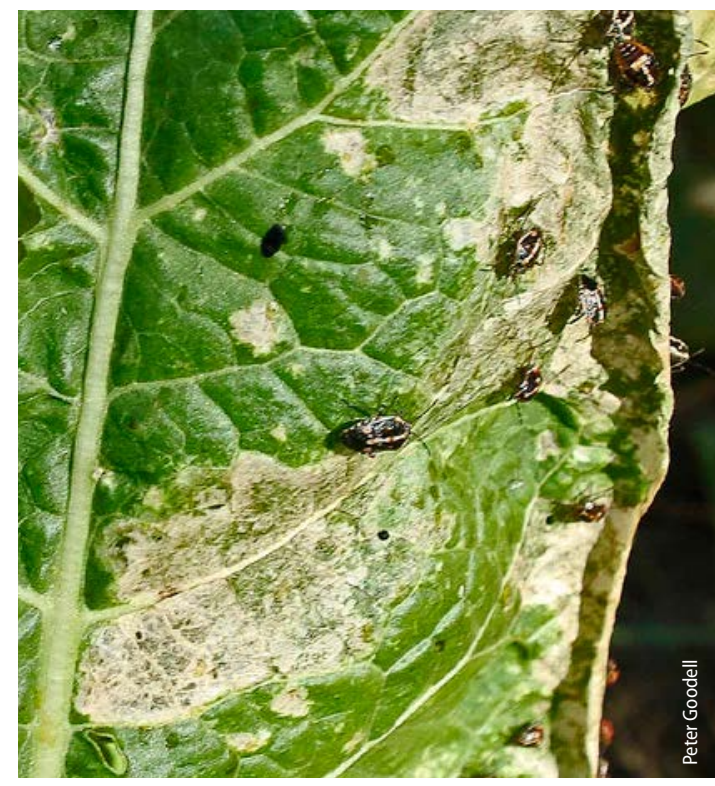

